\title{
Different Monsters: Traversing the uneasy dialectic of institutional and relational ethics
}

\section{Al Strangeways \\ Charles Darwin University \\ al.strangeways@cdu.edu.au}

\section{Lisa Papatraianou}

Charles Darwin University

lisa.papatraianou@cdu.edu.au

Keywords: ethics, relationships, Aboriginal research, resilience, schooling, university partnerships

\begin{abstract}
This paper presents a comic-strip to tell the story of an experience where we, the researchers, struggled to reconcile our institution's ethical requirements with the need to build respectful and reciprocal relationships with research participants, the essence of ethical practice. The core images of our comic-strip derive from Wallace and Lovell's monoprint, "Monstrous Breaches" (Lovell \& Wallace, in press). We respond to the artists' invitation to re-work their monoprint in order to better understand the "monsters" or dangers of our research world. We contend that traversing the spaces between institutional and relational ethics is itself a process that is often fraught with ethical dangers, "monsters" that researchers and institutions often overlook at our peril.

Critical interpretation and analysis of the comic-strip elicits three "monsters" that can be encountered in this space: 1) the deficit model that assigns "vulnerability" to all Aboriginal research participants and the implications of this; 2) the neo-paternalist assumption that participants share the institution's values and goals, resulting in measures that impinge on rather than protect participants' needs, and; 3) the friction between an institutional discourse that is built on certainty, replicability, and legalistic concepts of safety in contrast to a relational discourse that recognises uncertainly, responsiveness and interpersonal concepts of safety.
\end{abstract}


Figure 1. Al and Lisa's collaged comic strip, 'Different Monsters', 2017.
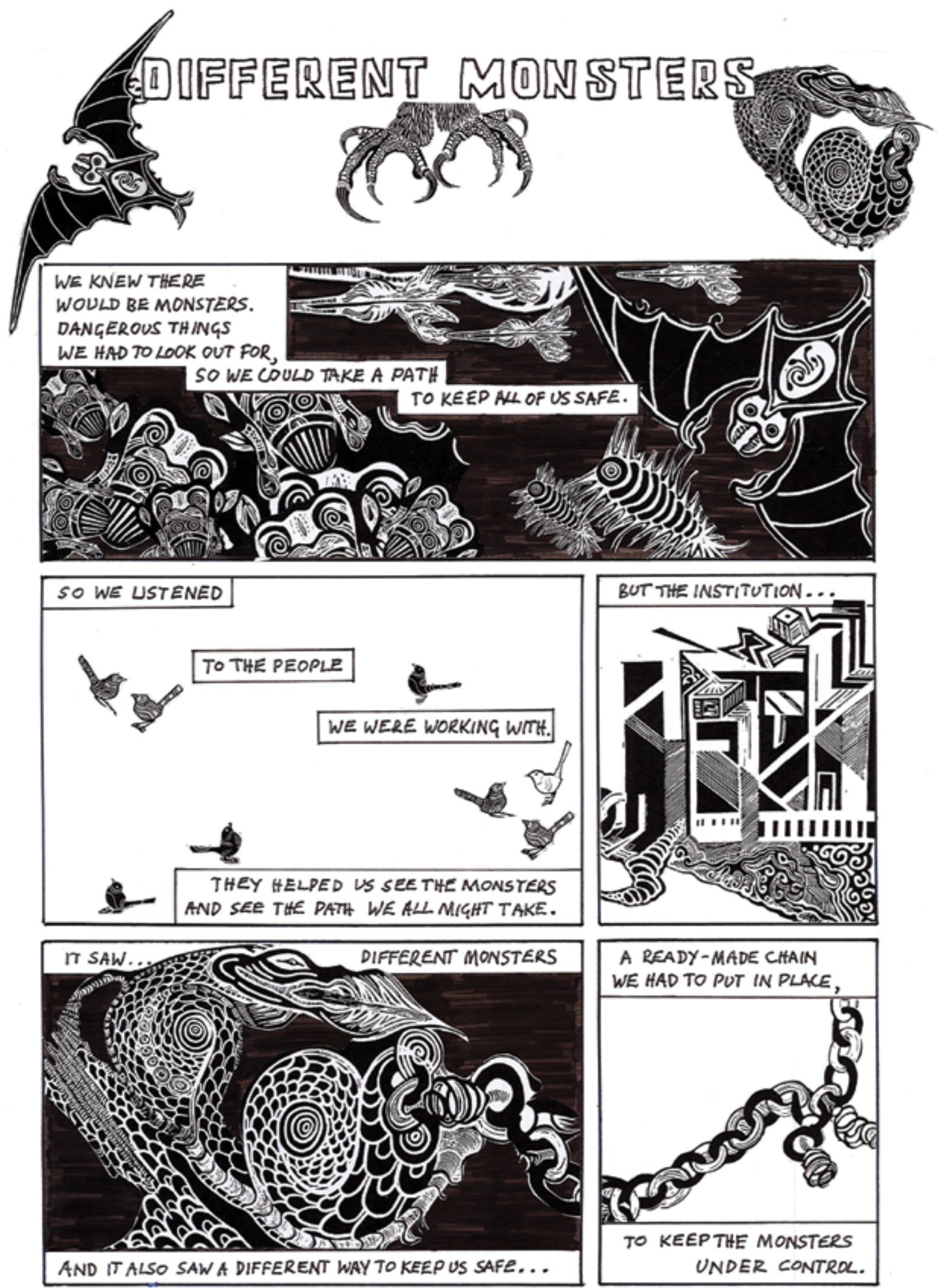


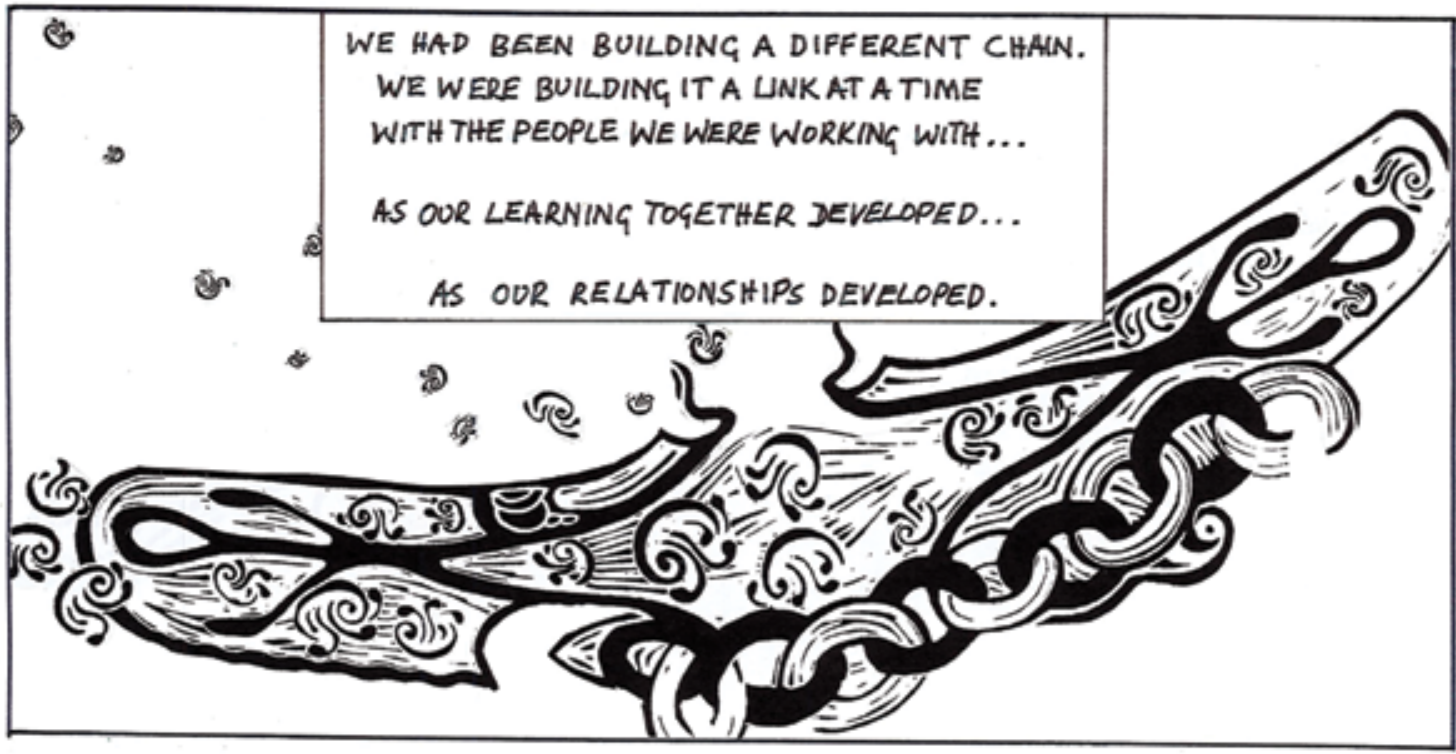

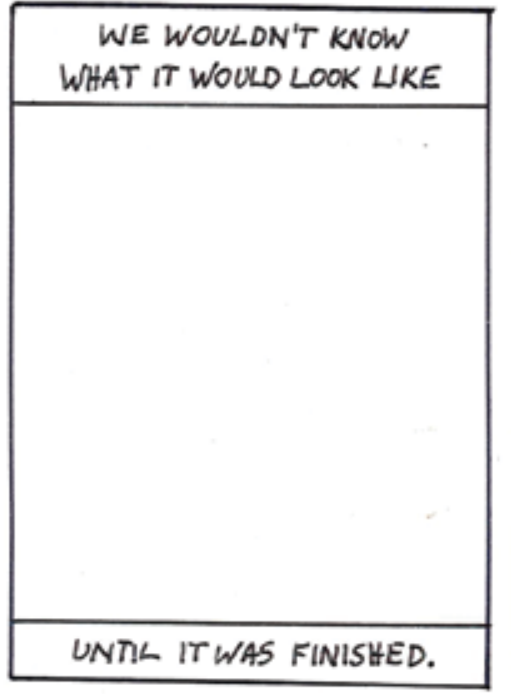

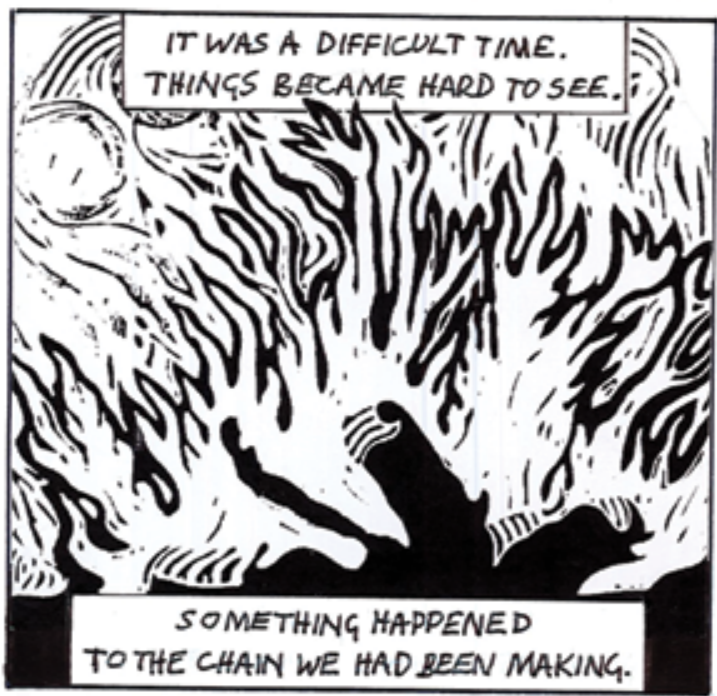

WE TRIED TO TALK TO THE INSTITUTION ABOUT THE DIFFERENT MONSTERS WE SAW AND THE DIFFERENT CHAIN WE WERE MAKING.

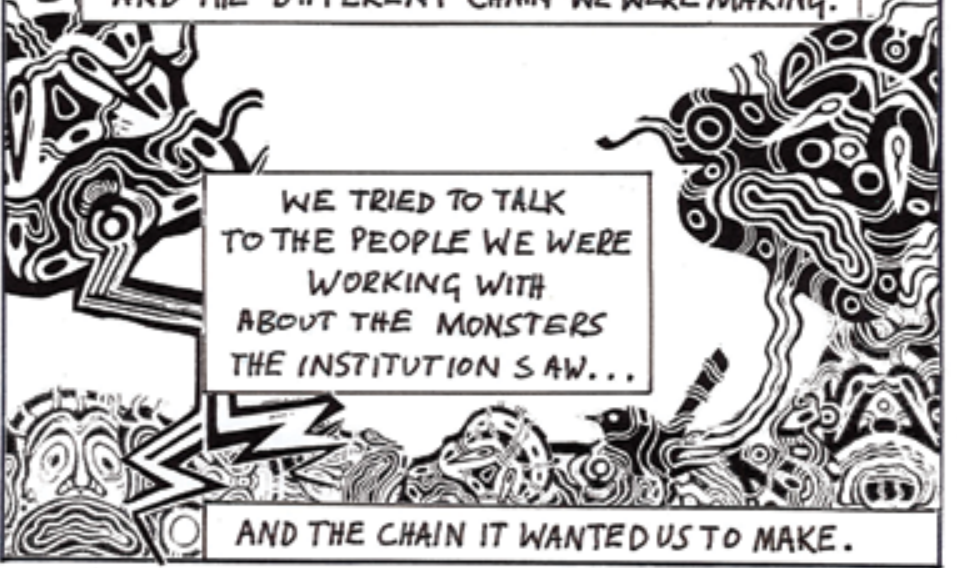

AND THE CHAIN IT WANTEDUS TO MAKE.

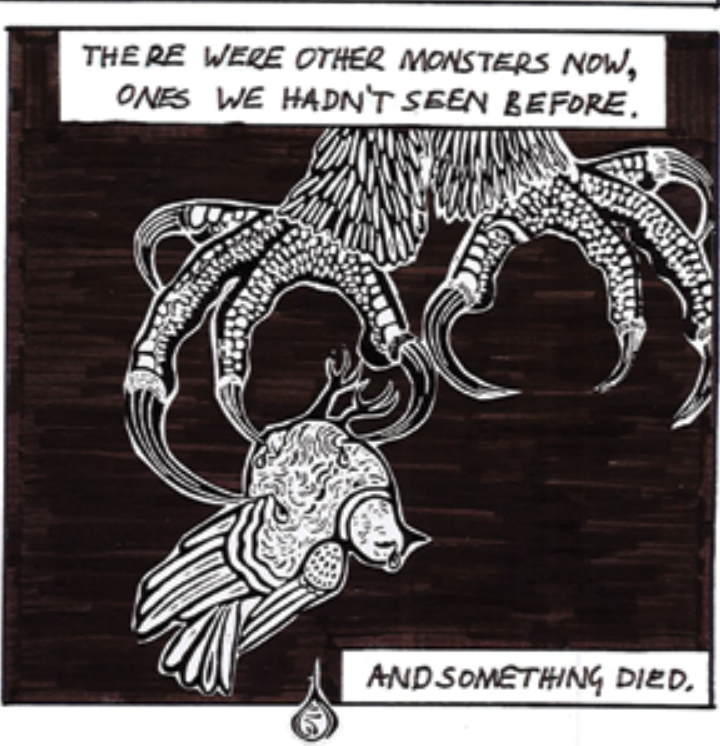




\section{Context and Rationale}

"Different Monsters" depicts the institutional boundaries and constraints that we experienced during the early stages of an Australian research project, entitled "Different Places, Different Faces: Understanding diverse students' resilience when moving between home and school cultures". The project aimed to build an understanding of resilience among culturally diverse students in Australia, identifying the challenges that they encountered, and the resources that they used while negotiating their everyday lives, both at home and at school. Three groups of young people participated in the research: 1) students from a remote Indigenous (Arrernte) school in central Australia, 2) students from a South Australian school with a significant cohort of refugee students, and 3) students from a South Australian school with a high proportion of international students who were living away from their families. To explore concepts of resilience, and how these young people consolidated their educational aspirations at the 'cultural interface', we employed visual, arts-based approaches in order to elicit culturally relevant accounts of participants' home and school lives, creating an authentic and nuanced understanding of their experiences which was respectful of their cultural context, and which could be used to foster the resilience and capacity of these students, and of their families and schools.

We developed the project through ongoing discussion with each of the schools, who had voiced their concerns over the individual and environmental resilience of their students. They wished to understand the challenges that these students faced, as well as provide better support that allowed them to more effectively manage the often-incongruent cultures of school and home. Two of the three schools provided dedicated funding to support the project, with the outcomes being used to develop a range of activities and materials including picture books and teacher-learning resources. We worked collaboratively with school leaders and teachers from each of the schools to create a series of arts-based workshops which offered an engaging and safe environment in which students could explore their resilience by identifying the challenges that they encountered, and the resources that they had used to overcome them. The workshops were co-delivered by a teacher and a member of the research team, with workshops being modified over time according to teacher and researcher insights, as well as the needs of the students.

In designing the project, careful consideration was given to the safeguarding of participants. While the project was intended to provide a collaborative and emancipatory account of resilience among diverse young people, from an ethical perspective, this group of participants possessed a range of potential vulnerabilities, which included their age, gender, cultural background, and experiences as minority groups, immigrants, refugees or asylum seekers (Liebenberg \& Ungar, 2009). It is often the case, as Groundwater-Smith, Docket and Bottrell (2015) explain, "The dynamics of gatekeeping may be more intense when children and young people belong to particularly marginalised groups" (p. 80). While this may be the case, our discussions with the school leaders focused on the emancipatory opportunities this research offered, with how it offered their students the opportunity to shape the support and services relevant for them, responding to the work of Theron and Malindi (2010) who note that many vulnerable groups have limited opportunities for input for services directly related to them.

The focus of our research raised additional ethical concerns, as studies on resilience often entail asking participants to explore experiences which some may find challenging or upsetting. Considering these potential risks, we implemented specific safeguarding measures in both the design and implementation of the project that we believed would negate or minimise the risk to participants. After presenting the project to schools and to the university Human Research Ethics Committee (HREC), school leaders were satisfied with the project design and were 
keen to proceed, but initial ethical approval was denied by the HREC, which requested further information on the project's ethical protocols in the Arrernte school setting. In particular, the HREC was concerned with why the project had not established an Aboriginal reference group to ensure that the research would be conducted appropriately in the Arrernte school setting. No such additional information was sought for the other participating schools.

To address this concern, we drafted a solution which minimised any impingement on participants without damaging the integrity of the research design, satisfying the demands of the HREC, and ensuring the project received institutional ethical approval. While a satisfactory outcome was achieved, the administrative ethics process in itself gave rise to feelings of frustration and disillusionment. When we shared this with colleagues who were working in similar contexts, it became evident that such experiences were not uncommon. Researchers who had worked with Indigenous participants on a variety of projects shared stories of how they had often felt hampered or compromised by the demands of administrative ethics, which did not seem to be responsive, relevant or compatible with ethical practices being used in the field.

We were also concerned about our temptation to adopt the measures which had been recommended by the HREC, even though these went against our better judgement, because this would expedite the process of gaining ethical approval, allow us to proceed with the field work, and ensure the schedule that had been negotiated with partnering schools was not delayed. We adapted the research design in line with the HREC request, rather than simply adopting their suggested measures, but the temptation to ignore or dismiss the tensions between the institutional and relational discourses in favour of expediency led the research team to question the ethics of our engagement with the administrative process. How often had research within similar contexts been compromised by the well-intentioned, yet ill-suited, administrative processes that such research had to follow? Reflecting on these experiences, this paper explores the uneasy dialectic between institutional and relational ethics, using the aforementioned project as an example to explore new ways of thinking, and inform future traverses between these two ethical landscapes and discourses.

\section{Methodology}

In this paper, we present a collaged comic-strip (Figure 1) as a means of representing and analysing the data produced through our experiences. This format has been selected because of the effectiveness of arts-based methods in addressing complexities such as those of the relationships between institutional and relational discourses. The original artwork from which the collage pieces were drawn itself represents a complex mediation between two discourses, as it is the product of collaboration between an Arrernte artist and elder and her non-Indigenous colleague. Arts-based approaches offer opportunities to see "phenomena in new ways, and to entertain questions about them that might otherwise have been left unsaid" (Barone \& Eisner, 1997, p. 96). The use of collage and the associated metaphors direct the viewer in generating meaning by interacting with the work, but ensure that these meanings "are not closed off, but rather open, multiple, suggested and implied" (Leavy, 2015, p. 241). In this embracing of uncertainty, an arts-based approach allows us to step away from dualistic and hierarchical structures when exploring the interfaces between different discourses and cultural practices: instead of looking for solutions to problems of the often-difficult landscape in which institutional and relational ethics can sometimes collide, the arts-based approach we use allows us to envisage the terrain and explore alternate pathways across it.

The comic-strip combines visual and narrative modes of representation, both of which foreground the embodiment of a lived experience and the affective-emotional component of that experience. In juxtaposing words and images, the comic strip creates an intertextual 
surface which extends to the relationship between the images in the strip and the text of the analytical writing accompanying it. As Sava and Nuutinen (2003) suggest, images and text cooperate in illustrating one another, uniting to form a hybrid, dialogic state or "third space" that is "strongly experiential, sensory, multi-interpretive, like a fleeting shadow, intuitive and ever changing ... the meeting place as a mixed stream of fluids, as something multi-layered, not known, always to be created anew, as the field of many understandings" (Sava \& Nuutinen, 2003 , p. 532). The comic-strip presented here operates both as a research product, through which the readers' analytical and the narrative modes of thinking can be engaged (Bruner, 1986), and as a research process, illustrating the path through which we, as researchers, came to understand this experience, and realise the implications that it has for future practice by researchers and institutions.

\section{Findings and Discussion: Different monsters}

We present our findings through interpretation and analysis of the comic-strip. Considering groups of cells portrayed within the comic-strip, this paper draws out the details of our experience, explores the background and implications of this experience with relation to the extant literature, and suggests what future steps could be taken by institutions and researchers to manage the monsters that threaten ethical research practice in diverse settings.

\section{1: Different monsters and the deficit model of "vulnerability"}

The monsters in the first cell take many forms: there are bat-like airborne things as well as sea and earth-bound creatures. They are all different sizes, locate themselves in different places and some are quite hard to see against the dark background. The textual "pathways" that navigate between the monsters are not clearly laid out, but rather map as the text progresses from its huddled position to the left of the cell into the space where the monsters are. The second cell presents a marked contrast in its light and space. The wrens here are often seen in central Australia as figures who share information and help people find their way to resources such as water or food and enable survival in a difficult landscape. Their diminutive size obscures the power and importance of what they have to offer. The spaces between them suggest the periods of our quiet listening and the pale background suggests our developing capacity to "see" or further understand the sensitive areas in which we were working as a result of this listening.

It was clear from the outset of the project that we would be entering a landscape of monsters. We wanted to discover and document the ways through which the resilience of culturally diverse young people could be understood and supported and knew our understanding of the monsters, or the ethical dilemmas facing us, was far from complete. In designing our research, we were keen to move beyond a deficit view of resilience, considering the challenges and resources used by young people as ones that were unique to their personal contexts, and not brought about through perceived vulnerability. A central feature of our research design and practice was to "listen deeply" (Wallace \& Lovell, 2009, p. 177) to the individuals with whom we were working. This approach is in the spirit and guidelines of the National Statement on Ethical Conduct in Human Research (NHMRC, 2015) which serve to guard against research practices that impinge on the rights and safety of the people participating, with particular attention to people who, because of their social status, are potentially more vulnerable than others.

Deficit models have justified using these differences or vulnerabilities as a way of explaining resilience, but in doing so often neglect the fact that there are key elements of resilience 
which are common across all groups and populations. No one group is seen as being more vulnerable than the other; rather, resilience occurs through the same mechanisms in all groups, but is uniquely tied to participants' individual contexts. As Liebenberg and Ungar (2009) argue, all forms of research need to ensure that the approach used is contextually attuned to the population being studied. In Australia, as well as in Canada, research which involves Aboriginal people must follow specific ethical protocols, which need to be met in addition to the standard institutional ethics required for all research. When working with diverse groups of people, issues of power invariably arise, and these ethical protocols have been established to prevent exploitation or the abuse of power, among both participants and researchers. Our proposed research study included young participants, who in themselves require additional ethical consideration, so we were acutely aware of the need for robust ethical procedures to safeguard participants on the grounds of both their age and their cultural background.

The suitability of existing ethical procedures in this area appears to have been overlooked to date. A review of ethical conduct in research across international settings and ethical bodies found that no distinction was made between young people within diverse settings (Boothroyd, Stiles, \& Best, 2009). Furthermore, there are concerns that working with young people from diverse backgrounds can enhance the power differential between participant and researcher. As Liebenberg and Ungar (2009) suggest, "the very nature of the gap between adult researcher and youth participant is accentuated when issues of diversity (class, ability, gender, sexual orientation, race, etc.) are added" (p. 9). In considering these ethical concerns, our emancipatory-generative research design endeavoured to explicitly uphold, enact and embrace the six core values recognised as meaningful to Aboriginal and Islander peoples in all our contexts, those of "reciprocity, respect, equality, responsibility, survival and protection, and spirit and integrity" (National Statement on Ethical Conduct in Human Research, 2007, p. 62). By adhering to these values, symbolised in the acts of listening and learning to see of cell two, we hoped to alleviate ethical concerns, and ensure the research was participatory and contextually attuned to the young people who participated.

The tightly framed image of the institution in cell three consists of straight lines, geometric angles and only a limited number of doorways or windows to connect it to the more fluid shapes of the world around it. Environmental water and windlike forms butt up against this complex but monolithic structure with little evidence of impact. The monster the institution sees in cell four is very different to those monsters depicted in the opening cell. It seems to be either one monster, or a connected group with a strong family resemblance. Its snake-like scales form regular patterns on its sinuous loops in a continuous and organised design. The regularity of both surface texture and overall shape correspond with the regularity of the shapes that form the institution in the previous cell. This monster, like the institution before, sits firmly in the foreground, dominating the space - even overflowing the cell boundaries, obscuring anything else that might otherwise be seen.

We did not expect there to be such a difference between the monsters we saw and the monster the institution saw. Having ensured our research aligned with the core values set out in the National Statement on Ethical Conduct in Human Research, we were somewhat surprised by the HREC's request that we modify our application to further demonstrate recognition of and response to the heightened vulnerability of participants from the Arrernte school. All three groups of participants seemed to have potential vulnerabilities which were particular to their individual contexts. To position one group as being more vulnerable than another would immediately regress our research to a deficit model of resilience. Responding in this way to the particular damage done by an ugly history of colonising research practices in 
Aboriginal contexts seemed to be a form of colonisation in itself. While we acknowledged that this automatic positioning, or recognition of only a "single monster", with the National Statement (2007) was likely done in good faith, adopting a deficit model that would define all Aboriginal and Torres Strait Islander people as vulnerable immediately dismissed their agency, decision making and choice. As Hawkes, Pollock, Judd, Phipps, and Assoulin (2017, p. 31) note, the classification of all Aboriginal people involved in research as vulnerable ignores intracultural diversity and leads to the kind of "misrecognition" that, ironically enough, is warned about in an earlier iteration of the National Health and Medical Research Councils' Values and Ethics Guidelines itself. As the document states, "to misrecognise or fail to recognise (cultural difference) can inflict harm, can be a form of oppression, imprisoning someone [or a group] in a false, distorted and reduced model of being" (NHMRC, 2003, p. 3). Hawkes et al. (2017), argue that this form of misrecognition by HRECs can "discourage researchers and communities seeking to challenge an outdated research paradigm that has historically focused on 'Aboriginal problems' and could frustrate them in their efforts to contribute to the development of one that promotes Aboriginal-led solutions" (Hawkes et al., 2017, p. 32).

This process of othering, whereby research assigns particular vulnerabilities to an individual or group, is ingrained with outdated, deficit views of resilience, and hampers any prospect of providing authentic, contextually attuned accounts of resilience among diverse people. By removing this predetermination of monolithic vulnerability from our research, we hoped to offer a more accurate representation of the experiences of young people across diverse groups and settings, and in doing so, meet Liebenberg and Ungar's (2009) criteria for quality research, which need to "... reach across this us-them divide [... and] can no longer be just objectivity, but must also consider authenticity" (p. 9). As part of the emerging strengths-based literature on resilience among diverse groups and populations, our project endeavoured to contribute to this body of research and its capacity to give power back to what were once considered "vulnerable" groups, examining resilience as a function of their context, rather than in relation to a set of deficits and adaptations rooted in white-middle class values.

\section{2: Different chains and neo-paternalist assumptions}

The chain in cell five has already been glimpsed in the previous images of the institution and the monster the institution saw. It is very clearly an institutionally owned and crafted chain, one that is intimately bound up in the institution's idea of the monster, as suggested by the flow between cells four and five. While there is part of a similar chain- like structure in cell 6 , this is only one element of the image, which is dominated by the two human figures, who seem to be floating or dancing together amidst a stream of different sized link-like objects. They seem almost to be building the figure that encloses or protects them, perhaps using the chain to keep the monsters away rather than binding the monsters up.

The generative way in which we built the chain, or developed relational ethical safeguards, contrasted starkly with those the institution expected us to develop. The National Statement on Ethical Conduct in Human Research (NHMRC, 2015) describes the purpose of HREC's regulatory roles as ensuring that researchers operate in the "right spirit out of an abiding respect and concern for one's fellow creatures" (p. 2). In practice, however, it has been argued that these processes act as a way of over-determining the relationships between researchers and Indigenous communities, "forcing a highly bureaucratic procedure onto the research design" (Hawkes et al., 2007, p. 24). There is a distinct mismatch between the intentions of HRECs and the safeguarding processes that they put in place. Despite espousing the need for reciprocity, respect and equality when working with Indigenous communities), the rigidity of 
the ethical processes expected by HRECs often transgress such values as respect for other conceptions of consent. As Smith (2012) explains:

Asking directly for consent to interview can also be interpreted as quite rude behaviour in some cultures. Consent is not so much given for a project or specific set of questions, but for a person, for their credibility. Consent indicates trust and the assumption is that the trust will not only be reciprocated but constantly negotiated - a dynamic relationship rather than a static decision. (p. 137)

These institutional processes thus risk disempowering the people they intend to protect by "denying them their right to determine for themselves how consent should be given and consultation undertaken" (Hawkes et al., 2017, p. 38).

Although we had described the intercultural collaborative research design process as one that incorporated contributions from teachers, families and students to ensure all parties had a valued, authentic voice, we were asked to include an additional reference group into the research design, or failing that, specify why one was not required. Having already sought the participation and trust of participants, we were acutely aware that we needed to employ processes that did not attempt to speak for the participants. Implementing an Aboriginal reference group in the design would unearth additional concerns around participants' privacy and confidentially, whereby the reference group would be provided with potentially intimate knowledge of the participant group and community with whom we were working. The ethical processes, or chain, that we had built into our research were designed to respect and actively listen to participants' needs, and through these, to address the power differentials between the roles and relationships of researchers and participants (Canella \& Lincoln, 2011, p. 82). As Denzin and Giardina (2007) argue, listening to participants' authentic voice acts as a way of decolonizing, honouring and reclaiming indigenous cultural practices (p. 35).

Our approach towards achieving a more participatory research design was to use critical radical ethics, a process that moves away from universal and generalised ethics, towards one that is relational and collaborative (Canella \& Lincoln, 2011). Our focus was on process rather than administration, and we built on previous professional relationships between the researchers and the Indigenous and non-Indigenous staff and students that had developed over several years in activities including professional learning workshops, classroom visits and a portraiture exhibition project. Conversations that were significant to the design and conduct of the project occurred in informal and unplanned contexts. In the planning stages of the project, the overall design, as well as the aims and challenges of the research, were determined during 'Friday after-work drinks' when the classroom teacher was spending a weekend in Alice Springs. In another example, after an early workshop, one member of the research team had given the class's Assistant Teacher a lift into town, during which they had discussed how comfortable students were in working with the arts materials, and how Arrernte language could be better integrated into their learning about colour. Discussions about students' challenges and successes in expressing abstract ideas through non-symbolic shapes were also undertaken with a community elder and a retired teacher during a shared studio session one weekend. Feedback from students before and during the workshops about their interest in the project and the arts processes occurred during recess breaks and before and after school when individuals or groups would approach one of the researchers and ask about "doing more art together".

While these strategies diverged from the formal group meetings recommended by the HREC, they were used because they specifically aligned with the six core values and principles which are central to research among Aboriginal and Torres Strait Islander communities outlined 
earlier. Our chain and the chain-making process might not have been as recognisably chainlike as the institution expected, but we were confident in its effectiveness. We used these strategies because they offered us a way to capture the authentic voice of diverse young people from the perspective of their context, actively listening to participants rather than forcing their involvement. Reflecting on research from an Indigenous standpoint, Glesne (2007, in Smith, 2012) summarises "If you want to research us, you can go home. If you have come to accompany us, if you think our struggle is also your struggle, we have plenty of things to talk about" (p. 171).

The intention of our research design was to avoid the neo-paternalist assumption that tends to dominate cultural research and which suggests that participants understand and share the same values and goals as the institution. Working from this assumption, HRECs are free to implement any ethical measures that they see fit, without considering how they may impinge on participants' needs, as the needs of the institution and the participants are one. Employing dominant neo-paternalist approaches silences diverse and alternate discourses (Liebenberg \& Ungar, 2009, pp. 12-13) so we employed strategies to counter such approaches, by actively listening to the needs of participants, and avoiding any measures which artificially spoke for them. By taking a collaborative approach, which involved input from teachers, families and students, we sought to mitigate the inherent power differences between ourselves as researchers, and young people as participants, ensuring that everyone involved in the research had the opportunity to decide on key criteria used within the discussions of resilience. Furthermore, by contextually positioning our research, we intentionally avoided implementing any oppressive methodologies, such as othering, imposing externally determined perceptions of participants' deficits and vulnerabilities in explaining their resilience. Through this, we hoped to go against the tide of dominant Western research models which "very often attempt to enforce their best fit practices within contexts that they believe they understand" (Liebenberg \& Ungar, 2009, p. 11). As Smith maintains, "Indigenous people and other groups in society have frequently been portrayed as the powerless victims of research, which has attributed a variety of deficits or problems to just about everything they do," with much of such research failing to subsequently improve the conditions of the people being researched (2012, p. 178). Therefore, above all, we wanted our research to use ethical processes that treated participants as active subjects in the construction of their world and ensured that their voices were heard specifically in relation to their historically located context (Liebenberg \& Ungar, 2009, p. 13). By creating a "different chain" over the course of the project, we actively worked to promote the values of respect, reciprocity, equality, responsibility, protection and integrity by presenting an exploration of resilience among a contextually specific group of Indigenous young people, rather than a culturally homogenous series of results which could be generalised to reflect the resilience of youth globally or young Indigenous Australians.

\section{3: Other monsters and inter-discourse friction}

The grimaces and contortions on the faces in cell eight represent our struggle to communicate authentically and in ways that would be understood by the very different groups. The geometric speech lines emerging from the mouth of the left-hand face reflects the angular rigidities of the institutional discourse; the riverlike flow and the small bird emerging from the right-hand face recall the nature of relational discourse: the fluidity and uncertainty of the "different chain" and the importance of listening and learning to see. The rising "tide" of anxious faces seems almost to be swamping these speech lines, however, suggesting that the attempts to talk to the different groups were not completely successful. This image of watery destruction is replaced by one of fire and smoke in the next cell: clarity 
and focus are lost in the smoke and the fire seems all consuming, reaching up into the text, suggestive more of destruction than of regeneration. In contrast is the quiet poignancy of the final image, starkly positioned against the black background shared by all the monsters in this strip. The bird at the bottom of the cell is more dove-like than wren-like, suggestive of hope perhaps or peace between dissonant groups. The "other monster" we see here is massive, but only marginally glimpsed, enhancing the reader's sense of disquiet.

Attempting to address the incongruence between institutional and relational ethics was a complex challenge and one that we felt we did not successfully meet. In responding to the HREC's request to incorporate an Aboriginal reference group into the project, our counterproposal offered the creation of an "informal reference group", which would be comprised of the elders, teachers and family members that we had already been talking to about the project. While this offered an easier route than arguing against the HREC's decision and attempting to convince them that a "reference group" was not an appropriate overlay onto the research design, it posed a dilemma for the research team of whether to stick with what they believed was right, or to adopt the HREC's measures for the sake of expediency. In seeking opinions from the research participant community, we asked three individuals who had been working with us on the project for permission to name them as members of the informal reference group. Reassurances were made that this would not involve any additional layers of administration, and that their participation would continue on as before. The three individuals were bemused by this request; as one responded, "We wouldn't be doing this if I thought it was a bad idea." All three appeared to be resigned to the situation that the institution would, with good intentions, impose its own named protocols onto the research, and that both they and the researchers would inevitably be required to work around them. While this was a workable solution, as researchers we felt as if we'd betrayed a certain level of trust that had been generated during the collaborative generation of the project. We had let "our" institution impose itself on our research relationships in a way that was clumsy and incomprehensible, failing to protect the participants from the administrative processes they did not value, and demonstrating a lack of understanding between us and our institution, and a lack of agency or power on our part in our dealings with the institution.

This experience of "trying to talk" in good faith but in different ways to different groups demonstrates the friction that results when an institutional discourse - which is built upon certainty, replicability, and legalistic concepts of safety - interacts with a relational discourse - which values uncertainty, responsiveness and relational concepts of safety. While HREC restrictions are well-intentioned and designed to safeguard the wellbeing of all participants, there must be protocols for deviating from such restrictions where research works towards supporting the needs of local cultures and actively attempts to minimise the burden on participants. One such protocol might, as Boothroyd et al. (2009) suggest determine the reason for deviation:

As a general rule, a strategy's being more convenient, cheaper, or easier is typically not a good enough reason to deviate from the recommended guidelines. In contrast, adapting procedures to better conform to local cultural norms or to minimize participant burden provides a more compelling rationale for departing from preferred standards is working to support the needs. (p. 28)

Where research is cognisant and contextually attuned to local cultural norms, ethical procedures should be modifiable in order to return strength and power to the community being studied. These practices need to be built around a backdrop of collaboration and reciprocity between researchers and participants. As researchers, we need to adhere to ethical obligations at all 
times, and we need to do this in a way that is sensitive and flexible to the considerations of the participants (Liebenberg \& Ungar, 2009). Such obligations also extend to an increased accountability for our research, translating our findings into appropriate programs and policies which can benefit the local community. One difficulty this poses is retaining "objectivity" within the research, balancing the moral obligation to ensure that the research is both appropriate and ethically sound with adherence to standards of authenticity, reliability and validity. Reflective process can be used to achieve this, by continually reviewing outcome data, and assessing the direction and authenticity of the research throughout the duration of the project (Liebenberg \& Ungar, 2009, p. 18). Imposing procedures that are incongruent with participants' individual context serves both to erode relational trust and to undermine the authenticity of the research. We need to engage in ethical processes that are designed to honour the strengths of the community being studied. Writing about resilience research, Liebenberg and Ungar (2009) argue that future research must seek "innovation in methodology and creating dialogue across research paradigms in order to find new ways of answering difficult questions. In this process we will transform what we define as ethical research when studying resilience" (p. 18).

Something happened to the relational ethics we were building when we overlayed the "informal focus group," and something died, for the researchers, if not for the participants, as a result of this experience. Just as we felt the participants lost a measure of trust in us as co-inquirers, so we too lost trust in the capacity of the administrative process to offer a path that respected both the institutional need for clear, replicable and legally sound protections and the needs for such protections to be respectful of participants' differing values and goals. While we observed the HREC's measures, we found ourselves shifted into the "...perpetuation or maintenance of inquirer-orientated power (as savior, decolonizer, or one that would empower)" (Canella \& Lincoln, 2011, p. 82). This paper is, however, an endeavour to engage in what Boothroyd et al. (2009) describe as "moral progress [our italics] by acknowledging our ethical obligations and adhering to sensitive and flexible protocols that take into consideration the nation, tribe, culture and values of the targeted group" (p. 67). While we felt we were not successful in meeting the challenge of "moral progress" when traversing the dialectic between institutional and relational ethics during the project, we have used this paper to maintain our reflective processes, not only during but after our work with the projects' participants, as part of the broader imperative to continually review, adjust and assess our research approaches with diverse youth to ensure they are ethically sound and culturally appropriate (Boothroyd et al., 2009).

\section{Conclusion: Keeping us all safe from the other monsters}

We as researchers need to position ourselves to guard against our potentially deficit view of administrative ethics. We need to recognise the friction between administrative and relational ethics, while potentially destructive, can generate ethical practices that are more robust and authentic. The chain can be tempered or strengthened from its exposure to the fire. Researchers need to keep "talking to the institution" and extend our practice of ethical relational practices to them by building relationships with HRECs. As Smith (2012) asserts, “... researchers who choose to research in the margins are at risk of being marginalized themselves in their careers and workplaces. One strategy for overcoming this predicament is to 'embrace' the work and commit to building a career from that place" (p. 213). In order to embrace our work at the margins, we need to create a parallel practice that reflects the relational ethics of our interaction with research participants, and continually engage in discourses that nurture the spirit of resilience, critical engagement, and cultural sensitivity. As Smith (2012) maintains;

Cultures are created and reshaped; people who are often seen by the mainstream as dangerous, unruly, disrespectful of the status quo and distrustful of established 
institutions are also innovative in such conditions; they are able to design their own solutions, they challenge research and society to find the right solutions. Researchers who work in the margins need research strategies that enable them to survive, to do good research, to be active in building community capacities, to maintain their integrity, manage community expectations of them and mediate their different relationships (p. 213).

Researchers need to increasingly grasp their own agency in their relationships with the institutions to create the necessary dialectic to respectfully challenge HREC's assumptions and ossified practices. As Liebenberg and Ungar (2009) assert, we need to create "...dialogue across research paradigms in order to find new ways of answering difficult questions" (p. 19).

While HREC's ethical processes are largely concerned with unequal power relationships between the researchers and participants, little attention has been given to the unequal power relationship between HRECs and researchers, and its potential dangers. HRECs need to consider modifying their legalistic and inflexible processes to better recognise and value the social and cultural practices of diverse groups, and the individual agency of researchers and research participants. By developing the capacity to "listen deeply" (Wallace \& Lovell, 2009, p. 177) to researchers, participants and communities, HRECs could more genuinely address unequal power relationships by incorporating the voices of researchers and participants to inform ethical process. Just as researchers need to "listen deeply" to participants, so too do institutions need to "listen deeply" to researchers.

Extending the six core values of the National Statement on Ethical Conduct in Human Research (NHMRC, 2015) to guide the relationships between researchers and HRECs, just as they guide those between participants and researchers, will allow us to progress from dominant western models of thought that enforce oppressive research methods to embrace inclusion. There is no on-size-fits all approach to navigating the complex landscape of ethical processes that suits the purposes and goals of researchers, participants and institutions. This complex space reflects what Spiro, Coulson, Feltovich and Anderson (1989, p. 1) describe as an "ill-structured domain", a difficult space in which to operate when there are no consistent patterns of application to follow. There are risks to applying a rules-based approach that neglects the value of context dependent-knowledge to inform decision making (Flyvjberg, 2004). Overreliance on a rules-based approach risks neglecting to build the kinds of context-dependent knowledge that are central to responsive decision making in ever different contexts.

Navigating this complex landscape requires a new lens through which to recognise and address its challenges. A resilience perspective would offer researchers and HRECs opportunities for the building of resources to address the ethical relational challenges discussed in this paper. Through our research, we retain that "the study of resilience has the potential to do things differently" (Liebenberg \& Ungar, 2009, p. 9) in this space. Ungar (2012) describes the potential for growth in resilience as "morphogenesis" (p. 13), moving forward to a new state of practice, rather than simply recovering from challenging experiences. Such an approach aligns with Rutter (2012) who maintains, "Good physical health is not fostered by avoiding all contact with infectious agents. Rather it is fostered by encountering such agents and dealing with them successfully" (p. 36). Therefore, in order to focus on addressing challenges in this space, we must recognise the value of difficult experiences, such as those described in this paper, in order to develop resilience and therefore growth in our ethical processes. This perspective offers researchers, institutions and participants an optimistic direction in which we can proceed, and a vision of collaboratively identified pathways and resources that will enable us to all successfully traverse the ill-structured domain of ethical practice. 


\section{Acknowledgements}

We sincerely thank our colleague Dr Neil Tippett for his critical eye and feedback on this paper. We also thank the schools for their contributions to this research and their commitment to supporting the needs of all students in their schools. 


\section{References}

Barone, T., \& Eisner, E. W. (1997). Arts-based education research. In R. M. Jaeger, \& T. Barone (Eds.). Complementary methods for research in education. (pp. 95-109). Washington, DC: American Educational Research Association.

Boothroyd, R. A., Stiles, P. G., \& Best, K. A. (2009). The ethical conduct of research involving children in international settings. In L. Liebenberg and M. Ungar (Eds). Researching resilience. (pp. 26-74). Toronto: University of Toronto Press.

Bruner, J. (1986). Actual minds, possible worlds. Cambridge, MA: Harvard University Press

Canella, G. S., \& Lincoln, Y. S. (2011). Ethics, research regulations, and critical social science. In N. K. Denzin \& Y. S. Lincoln (Eds). The Sage handbook of qualitative research (4th ed) (pp. 81-90). London: Sage.

Denzin, N. K. \& Giardina, M. D. (2007). Qualitative inquiry and social justice: Toward a politics of hope. New York: Routledge.

Flyvjberg, B. (2004). Five misunderstandings about case-study research. In C. Seale., G. Gobo., J.F. Gubrium, \& D. Silverman (Eds.), Qualitative research practice (pp. 420-434). London: Sage.

Groundwater-Smith, S., Docket, S., \& Bottrell, D. (2015). Participatory research with children and young people. London: Sage.

Hawkes, G. L., Pollock, D., Judd, B., Phipps, P., and Assoulin, E. (2017). Ngapartji Ngapartij: Finding ethical approaches to research involving indigenous people, Australian perspectives. ab-Original, Journal of Indigenous Studies and First Nation and First People's Cultures 1(1), 17-41.

Leavy, P. (2015). Method meets art: Arts-based research practice (2nd ed.). New York: The Guilford Press.

Liebenberg, L., \& Ungar, M. (2009). Introduction: The challenges in researching resilience. In L. Liebenberg and M. Ungar (Eds). Researching resilience. Toronto: University of Toronto Press.

Lovell, J., \& Wallace, K. (in press). The making of Monstrous Breaches: An ethical global visual narrative. Learning Communities: International Journal of Learning in Social Contexts.

National Health and Medical Research Council (NHMRC). (2015). National Statement on Ethical Conduct in Human Research 2007 (Updated May 2015). Canberra: National Health and Medical Research Council, Australian Research Council, and Australian Vice-Chancellors' Committee. Retrieved from https://www.nhmrc.gov.au/guidelines-publications/e72.

National Health and Medical Research Council (NHMRC). (2003). Values and Ethics: Guidelines for Ethical Conduct in Aboriginal and Torres Strait Islander Health Research. Canberra: National Health and Medical Research Council, Australian Research Council, and Australian ViceChancellors' Committee. Retrieved from https://www.nhmrc.gov.au/guidelines-publications/e52

Rutter, M. (2012). Resilience: Causal pathways and social ecology. In M. Ungar (Ed.), The social ecology of resilience: $A$ handbook of theory and practice (pp. 33-42). London: Springer.

Sava, I., \& Nuutinen, K. (2003). At the meeting place of work and picture: Between art and inquiry. Qualitative Inquiry, 9(4), 515-534.

Smith, L. T. (2012). Decolonizing methodologies: Research and Indigenous peoples. (2nd ed). Dunedin,New Zealand: Zed Books.

Spiro, R. J., Coulson, R. L., Feltovich, P. J., \& Anderson, D. K. (1989). Cognitive flexibility theory: Advanced knowledge acquisition in ill-structured domains. In S. Vosniadou \& A. Ortony (Eds.), The tenth annual conference of the Cognitive Science Society (pp. 498-531). Hillsdale, NJ: Lawrence Erlbaum. 
Theron, L., \& Malindi, M. (2010). Resilient street youth: A qualitative South African study. Journal of Youth Studies, 12(6), 717-736.

Ungar, M. (2012). Social ecologies and their contribution to resilience. In M. Ungar (Ed.), The social ecology of resilience: $A$ handbook of theory and practice (pp. 13-31). London: Springer.

Wallace, K. K., \& Lovell, J. (2009). Listen deeply, let these stories in. Alice Springs: IAD Press. 